\title{
Treatment of Esthesioneuroblastoma and Nonsmall Cell Lung Cancer with Phenylbutyrate
}

\author{
Stanislaw R. Burzynski, Eva Nagy-Kubove \\ Burzynski Clinic, Houston, USA. \\ Email: srb@burzynskiclinic.com \\ Received August $10^{\text {th }}, 2011$; revised September $9^{\text {th }}, 2011$; accepted September $16^{\text {th }}, 2011$.
}

\begin{abstract}
Esthesioneuroblastoma is a malignant tumor, arising in the upper nasal cavity, that could spread to the frontal lobe of the brain as well as metastasize to the lymph nodes. Due to the low incidence of this tumor, FDA-approved treatment modalities do not exist and clinical trials have not been performed. We present an interesting case of a 66-year-old female, diagnosed with Kadish stage B esthesioneuroblastoma and stage IIA nonsmall cell carcinoma of the lung, who benefited from our treatment. Both malignancies were diagnosed in 2002 at which time the patient consented to undergo left upper lobectomy for her lung cancer, but she refused the craniofacial resection and radiation therapy recommended for treatment of her esthesioneuroblastoma. From 2003 to 2004 she received treatment at the Burzynski Clinic with oral sodium phenylbutyrate $(0.2 \mathrm{~g} / \mathrm{kg} /$ day $)$. She tolerated the treatment very well without significant adverse events. Gradual reduction in her tumor size was confirmed by repeat MRIs. From treatment start in March 2003 to December 2003 her tumor decreased by 40\%. Subsequent MRI from March 2004 revealed increased tumor size, which, however, was still a 13\% reduction from the baseline MRI. What is important to mention is that in addition to shrinkage of the esthesioneuroblastoma, the patient obtained the clinical benefit of 3.5-years longer survival than was predicted for her lung cancer - whereas the median survival for a patient with stage IIA adenocarcinoma of the left upper lobe of the lung is approximately two years, our patient survived more than five and a half years. The effect of phenylbutyrate $(P B)$ and its metabolite phenylacetate on neuroblastoma and lung cancer is documented by numerous preclinical studies and is also evident in this case. It is proposed that the activity of these two compounds is mediated through increased expression of the p21 tumor suppressor gene. $p 21$ is a strong inhibitor of cyclin-D and cyclin-dependent kinase 4, which contribute to undifferentiated phenotype in neuroblastoma and are instrumental in cell cycle progression from $G_{1}$ to $S$ phase. It is hoped that future research and combination of $P B$ with other chemotherapeutic and targeted agents will provide better control of esthesioneuroblastoma and lung cancer.
\end{abstract}

Keywords: Phenylbutyrate, Esthesioneuroblastoma, Olfactory Neuroblastoma, Nonsmall Cell Lung Cancer, Phenylacetate

\section{Introduction}

Approximately 1000 cases of esthesioneuroblastoma (olfactory neuroblastoma) have been reported in world literature since it was first described in 1924-amounting to less than 50 cases a year [1,2]. Despite the lack of support for single-modality treatment regimens, a substantial number of patients are treated by surgery or radiotherapy alone, with some patients receiving cisplatinbased chemotherapy [2-4].

Sodium phenylbutyrate (PB) is an FDA-approved drug for urea cycle disorders, and it is also indicated for the treatment of primary and recurrent glioma and acute promyelocytic leukemia $[5,6]$. PB is partially metabo- lized in the human body into phenylacetate (PN) [7]. Both PB and PN have been extensively studied for their effect on neuroblastoma [8]. Integration of PB into neuroblastoma therapy has been highly recommended [9]. Previous studies reveal that PB has cytotoxic effect on human neuroblastoma, and that it can be combined with cisplatin in novel chemotherapy regimens [8]. PB is a histone deacetylase (HDAC) inhibitor. New publications recommend the use of such FDA-approved drugs for the treatment of neuroblastoma [10,11].

Here we report the treatment of esthesioneuroblastoma with $\mathrm{PB}$ as a single agent.

\section{Case Report}

A 66-year-old Caucasian female was admitted to Burzyn- 
ski Clinic (BC) on March 27, 2003, and was evaluated by Senior Oncologist Robert I. Lewy, M.D., F.A.C.P. She complained of fleeting pain in her forehead and left nasal ala, occasional positional dizziness, stiffness in the occipital area, productive cough with green discoloration, loose frequent stools from her previously diagnosed ulcerative colitis, stress incontinence, osteoarthritis in the large joints, left cheek numbness, and depression. She lost $14 \mathrm{lbs}$ in five months, but she was able to carry on normal activity with effort and some symptoms of her disease (Karnofsky Performance Status 80). After smoking two packs of cigarettes per day for 16 years, she quit smoking in 1997. She reported alcohol intake of one to two drinks on occasion; and she denied intravenous and recreational drug use.

The patient was healthy until February 2002 when she developed a bout of epistaxis, which recurred in August, in addition to pain she developed in the left maxillary area. She initially saw her dentist and local physician and was subsequently referred to an ENT specialist in the department of otolaryngology at a local medical university, where a left ethmoid sinus tumor was discovered. In November 2002 she underwent endoscopic debridement with grossly positive margins. Pathology revealed an esthesioneuroblastoma. Her case was reviewed at an ENT tumor conference at the local medical university. The definitive diagnosis was esthesioneuroblastoma, grade 1, Kadish stage B. She was advised to consider tumor resection followed by radiotherapy.

During her evaluation for esthesioneuroblastoma, she was found to have a tumor in the upper lobe of the left lung. On December 13, 2002, she underwent a left upper lobectomy with pathologic findings of nonsmall cell, moderately differentiated adenocarcinoma with one peribronchial node positive for metastatic disease (T1N1M0, stage IIA).

Upon presentation to BC, the patient was in good general condition. Her physical examination was remarkable only for a large birthmark on the left shoulder and left chest wall and a recent $24 \mathrm{~cm}$ post-thoracotomy scar in the left subaxilla. Her laboratory tests, including CBC, electrolytes, liver and kidney function tests, blood clotting factors and urinalysis, were grossly within normal limits. Baseline MRI of the brain, with and without contrast, from February 8, 2003, showed post-surgical changes consistent with resection of the left middle turbinate, a portion of the medial wall of the left maxillary anthrum, and multiple ethmoid air cells on the left side. Enhancing soft tissue mass was identified involving several remaining ethmoid air cells on the left side and, to a lesser extent, on the right side. The size of the lesion on sagittal images was $2.8 \times 1.7 \mathrm{~cm}=4.76 \mathrm{~cm}^{2}$. There was no evidence of intracranial metastatic disease. PET scan of the brain from March 28, 2003, revealed evidence of hypermetabolic changes at the base of the cranium in the anterior fossa in the region of the olfactory groove, bilaterally. There were also some changes in the anteriormost portion of the sphenoid sinuses extending into the region of the ethmoid area related to the patient's known lesion and surgical changes. Total body PET scan from March 28, 2003, revealed hypermetabolic changes in the chest wall of the mid-inferior and posterior areas, most likely related to fibrosis secondary to the patient's surgery. Chest x-ray from April 21, 2003, was status-post left lung resection.

Her diagnoses were as follows:

1) Esthesioneuroblastoma, grade 1, stage B.

2) Nonsmall cell carcinoma of the lung, stage IIA, status post surgery.

3) Ulcerative colitis since 1990 (quite severe at one point; total colectomy recommended).

4) Mild mitral valve prolapse since 1977.

5) History of psoriasis.

6) Osteoarthritis.

The senior oncologist at BC advised the patient to consider chemotherapy with etoposide and cisplatin in addition to retinoic acid, but the patient refused this.

After serious consideration of all available options, the patient began treatment with PB on March 31, 2003, with the final dose at $2 \mathrm{~g}$ po $6 \mathrm{x}$ a day $(0.2 \mathrm{~g} / \mathrm{kg} / \mathrm{day})$. Upon return home to northern United States, the patient was supervised by her local oncologist with continuous monitoring by the physicians at BC. Her treatment course was uneventful (without significant adverse events reported). Follow-up MRIs from August 21, 2003 and December 10, 2003 , revealed continued decrease in the size of the esthesiomeuroblastoma. The tumor measurements on $\mathrm{Au}$ gust 21, 2003, were $2.0 \times 1.6 \mathrm{~cm}=3.2 \mathrm{~cm}^{2}$; and on December 10, 2003, $2.4 \times 1.2 \mathrm{~cm}=2.88 \mathrm{~cm}^{2}$. Between February 8, 2003 and December 10, 2003, the product of the two largest perpendicular diameters of the tumor decreased by $40 \%$ from baseline as shown on the MRI from Figure 1.

MRI from March 17, 2004, revealed increased size of the lesion to $2.6 \times 1.6 \mathrm{~cm}=4.16 \mathrm{~cm}^{2}$. However, the tumor was still $13 \%$ smaller than the baseline measurement on MRI of February 8, 2003. The treatment was discontinued on April 8, 2004. As far as we know, the patient did not receive any further anticancer treatment, and she passed away on October 31, 2008.

Standard pharmacological treatment does not exist for esthesioneuroblastoma, which is a very rare malignant tumor. The patient decided not to have the extensive craniofacial resection which, according to scientific data, would not provide her any advantage of survival and would leave her seriously disfigured; and radiation ther- 


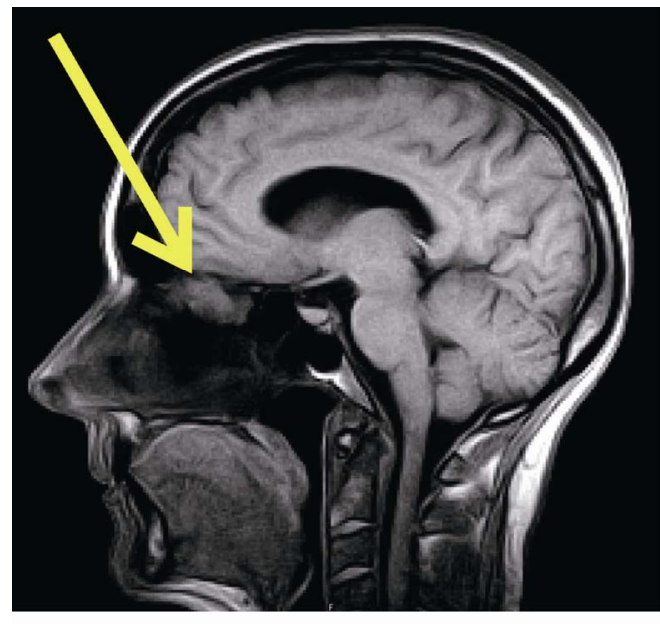

Baseline 02-08-2003

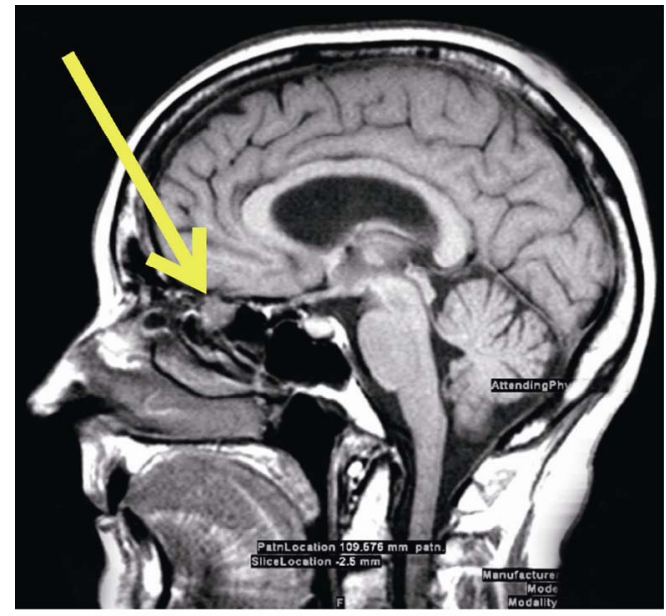

After 8 months of treatment 12-10-2003

Figure 1. MRI of the brain indicating shrinkage of the esthesioneuroblastoma.

apy would render her blind. Her Kadish stage B esthesioneuroblastoma carried a median survival of 12.5 years without any treatment, whereas her lung cancer carried the median survival of approximately two years. The median survival for adenocarcinoma of the left upper lobe of the lung was slightly over two years (25 months). In this respect, the treatment with PB contributed to excellent long-term survival over five and a half years with very good quality of survival.

The effect of PB against lung cancer is documented only by preclinical data [12-17]. The treatment with PB was the most logical choice for the patient's esthesioneuroblastoma. As documented by repeat MRIs, the patient obtained stabilization of her disease and near 50\% decrease of her tumor size and did not suffer any adverse events. She discontinued the treatment more than 13 months after she was informed about her increased tumor size. Considering the coexisting diagnosis and complex cancer history, with two distinctly different malignancies, the patient obtained excellent duration and quality of survival with the use of single-agent PB.

Numerous publications describe the activity of $\mathrm{PB}$ and its metabolite PN against neuroblastoma. A number of studies reveal that PB has cytotoxic effects on human neuroblastoma, and that it could be combined with cisplatin in novel chemotherapy regimens. Additional studies support the activity of PN, which synergizes with retinoic acid in inducing differentiation of human neuroblastoma and is recommended for treatment $[18,19]$. PN up-regulates retinoic receptor beta, which accounts partially for strong synergy between PN and retinoic acid against neuroblastoma [20,21]. Administered as a single agent, PN induces differentiation in human neuroblastoma [22]. The important aspect of the activity of PN and PB could be mediated through a two-fold increase of the expression of the p21 tumor suppressor gene, as shown in Figure 2. p21 inhibits cell cycle progression from $G_{1}$ to $S$ and from $S$ to $G_{2}$ phases. Activation of cyclin-D and CDK4 (cyclin-dependent kinase 4) maintains the undifferentiated phenotype of neuroblastoma and proliferation of malignant cells [23,24].

Cyclin-D and CDK4 promote $G_{1} / S$ progression. The entry to $G_{2}$ phase and crossing from $G_{2}$ to $S$ phase is pro moted by a complex of cyclin-E and CDK2. p27 (KIP1) inhibits CDK2, but is sequestered by a complex of cyclin-D/CDK4 and is destroyed by ubiquitination. Removal of p27 permits activation through phosphorylation of cyclin-E/CDK2 and entry to the $G_{2}$ phase. CyclinD/CDK4 and cyclin-E/CDK2 are inhibited by p21. PN, which is metabolized from $\mathrm{PB}$, doubles expression of the gene $C D K N 1 A$, which encodes p21 through demethylation of its promoter [24]. It is well understood that PB as a single agent is not sufficient to control esthesioneuroblastoma and nonsmall cell carcinoma of the lung over a long period of time. It is expected that a combination of PB with other anticancer drugs will provide better and longer control of cancer.

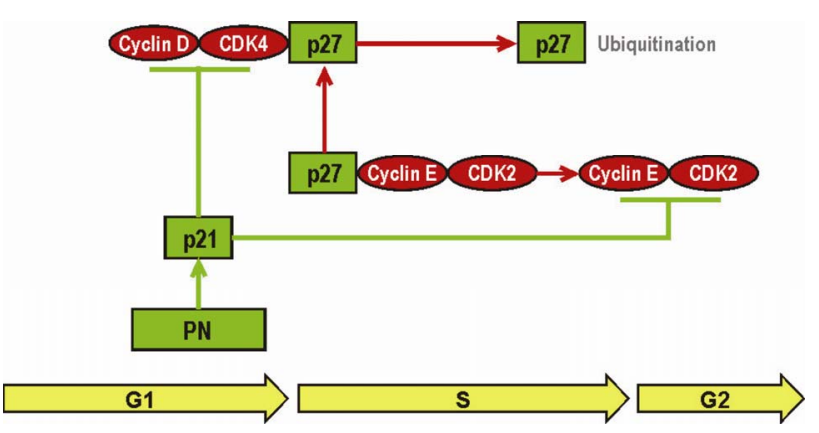

Figure 2. Inhibition of $\mathrm{G} 1 / \mathrm{S}$ and $\mathrm{S} / \mathrm{G}_{2}$ progression in neuroblastoma by PN (metabolite of PB). 


\section{Acknowledgements}

The authors express their appreciation to Robert I. Lewy, M.D., F.A.C.S., and Randall A. Stenoien, M.D., for their involvement in the care and evaluation of response.

\section{REFERENCES}

[1] P. J. Bradley, N. S. Jones and I. Robertson, "Diagnosis and Management of Esthesioneuroblastoma," Current Opinion in Otolaryngology \& Head Neck Surgery, Vol. 11, No. 2, 2003, pp. 112-118. doi:10.1097/00020840-200304000-00009

[2] E. A. McElroy Jr., J. C. Buckner and J. E. Lewis, “Chemotherapy for Advanced Esthesioneuroblastoma: The Mayo Clinic Experience,” Neurosurgery, Vol. 42, No. 5, 1998, pp. 1023-1028. doi:10.1097/00006123-199805000-00040

[3] H. F. Biller, W. Lawson, V. P. Sachdev and P. Som, "Esthesioneuroblastoma: Surgical Treatment without Radiation,” Laryngoscope, Vol. 100, No. 11, 1990, pp. 11991201.

[4] D. Jethanamest, L. G. Morris, A. G. Sikora and D. I. Kutler, "Esthesioneuroblastoma: A Population-Based Analysis of Survival and Prognostic Factors," Archives of Otolaryngology_Head \& Neck Surgery, Vol. 133, No. 3, 2007, pp. 276-280. doi:10.1001/archotol.133.3.276

[5] MicroMedex Thomson Healthcare USP DI, "Cumulative List of Orphan Product Designations and Approvals: Phenylbutyrate and Phenylacetate," Drug Information for the Healthcare Professional, Vol. 1, 2001, p. 3196.

[6] MicroMedex Thomson Healthcare USP DI, "Cumulative List of Orphan Product Designations and Approvals Phenylbutyrate and Phenylacetate," Approved Drug Products and Legal Requirements, Vol. 3, 2001, pp. 1/5/39.

[7] S. C. Piscitelli, A. Thibault, W. D. Figg, A. Tompkins, D. Headlee, R. Lieberman, D. Samid and C. E. Myers, "Disposition of Phenylbutyrate and Its Metabolites, PhenylaCetate and Phenylacetylglutamine,” Journal of Clinical Pharmacology, Vol. 35, No. 4, 1995, pp. 368-373.

[8] M. A. Pelidis, M. A. Carducci and J. W. Simons, "Cytotoxic Effects of Sodium Phenylbutyrate on Human Neuroblastoma Cell Lines," International Journal of Oncolology, Vol. 12, No. 4, 1998, pp. 889-893.

[9] M. A. Pelidis, M. A. Carducci and J. W. Simons, "Integration of Sodium Phenylbutyrate into Neuroblastoma Therapy,” 1996 ASCO Annual Meeting, Preclinical Experimental Therapeutics, Abstract 1596.

http://www.asco.org/ASCOv2/Meetings/Abstracts?\&vmvie w=abst_detail_view \&confID=29\&abstractID=10357

[10] K. De Preter, S. De Brouwer, T. Van Maerken, F. Pattyn, A. Schramm, A. Eggert, J. Vandesompele and F. Speleman, "Meta-Mining of Neuroblastoma and Neuroblast Gene Expression Profiles Reveals Candidate Therapeutic Compounds," Clinical Cancer Research, Vol. 15, No. 5, 2009, pp. 3690-3696. doi:10.1158/1078-0432.CCR-08-2699

[11] J. H. Schulte, S. Lim, A. Schramm, N. Friedrichs, J. Koster, R. Versteeg, I. Ora, K. Pajtler, L. Klein-Hitpass, S.
Kuhfittig-Kulle, E. Metzger, R. Schüle, A. Eggert, R. Buettner and J. Kirfel, "Lysine-Specific Demethylase 1 Is Strongly Expressed in Poorly Differentiated Neuroblastoma: Implications for Therapy," Cancer Research, Vol. 69, No. 5, 2009, pp. 2065-2071. doi:10.1158/0008-5472.CAN-08-1735

[12] A. J. Boivin, L. F. Momparler, A. Hurtubise and R. L. Momparler, “Antineoplastic Action of 5-Aza-2'-deoxycytidine and Phenylbutyrate on Human Lung Carcinoma Cells,” Anticancer Drugs, Vol. 13, No. 8, 2002, pp. 869874. doi:10.1097/00001813-200209000-00013

[13] X. Zhang, L. Wei, Y. Yang and Q. Yu, "Sodium 4Phenylbutyrate Induces Apoptosis of Human Lung Carcinoma Cells through Activating JNK Pathway," Journal of Cell Biochemistry, Vol. 93, No. 4, 2004, pp. 819-829. doi:10.1002/jcb.20173

[14] T. H. Chang and E. Szabo, "Enhanced Growth Inhibition by Combination Differentiation Therapy with Ligands of Peroxisome Proliferator-Activated Receptor-Gamma and Inhibitors of Histone Deacetylase in Adenocarcinoma of the Lung,” Clinical Cancer Research, Vol. 8, No. 4, 2002, pp. 1206-1212.

[15] C. M. Lyon, D. K. Klinge, K. C. Liechty and S. A. Belinsky, "DNA Demethylating Agents and a PPAR- $\gamma$ Agonist Cooperate to Induce Apoptosis in Lung Cancer Cell Lines, Cellular and Molecular Biology 2: DNA Methylation, Markers and Methylator Phenotype,” Proceedings of the American Association of Cancer Research, Vol. 47, 2006, Abstract 41. http://aacrmeetingabstracts.org/cgi/content/abstract/2006/1/ $10-\mathrm{a}$

[16] S. A. Belinsky, D. M. Klinge, C. A. Stidley, J. P. Issa, J. G. Herman, T. H. March and S. B. Baylin, "Inhibition of DNA Methylation and Histone Deacetylation Prevents Murine Lung Cancer,” Cancer Research, Vol. 63, No. 21, 2003, pp. 7089-7093.

[17] C. M. Lyon, D. M. Klinge, K. C Do, M. J. Grimes, C. L. Thomas, L. A. Damiani, T. H. March, C. A. Stidley and S. A. Belinsky, "Rosiglitazone Prevents the Progression of Preinvasive Lung Cancer in a Murine Model," Carcinogenesis, Vol. 30, No. 12, 2009, pp. 2095-2099. doi:10.1093/carcin/bgp260

[18] N. Sidell, R. Wada, G. Han, B. Chang, S. Shack, T. Moore and D. Samid, "Phenylacetate Synergizes with Retinoic Acid in Inducing the Differentiation of Human Neuroblastoma Cells,” International Journal of Cancer, Vol. 60, No. 4, 1995, pp. 507-514. doi:10.1002/ijc.2910600414

[19] R. K. Wada, J. Huang, J. Yamashiro, L. Shimoda and N. Sidell, "Combination Therapy with Retinoic Acid and Phenylacetate Induces Differentation and Myc DownRegulation in a Resistant Neuroblastoma Cell Line,” 88th Annual Meeting of the American Association for Cancer Research, San Diego, California, 1997, Abstract 581.

[20] N. Sidell, B. Chang, J. M. Yamashiro and R. K. Wada, "Transcriptional Upregulation of Retinoic Acid Receptor Beta (RAR Beta) Expression by Phenylacetate in Human Neuroblastoma Cells," Experimental Cell Research, Vol. 
239, No. 1, 1998, pp. 169-174.

doi:10.1006/excr.1997.3889

[21] R. Wada, G. Han, T. Moore, D. Samid and N. Sidell, "Effects of Phenylacetate and Its Interaction with Retinoic Acid on Human Neuroblastoma Differentiation. Effects of Phenylacetate and Its Interaction with Retinoic Acid on Human Neuroblastoma Differentiation," 85th Annual Meeting of the American Association for Cancer Research, San Francisco, California, April 1994, Abstract 2501.

[22] J. Cinatl, M. Mainke, A. Weissflog, H. Rabenau, B. Kornhuber and H. W. Doerr, "In Vitro Differentiation of Human Neuroblastoma Cells Induced by Sodium Phenylacetate," Cancer Letter, Vol. 70, No. 1-2, 1993, pp.
15-24. doi:10.1016/0304-3835(93)90069-L

[23] J. J. Molenaar, M. E. Ebus, J. Koster, P. van Sluis, C. J. van Noesel, R. Versteeg and H. N. Caron,” Cyclin D1 and CDK4 Activity Contribute to the Undifferentiated Phenotype In Neuroblastoma,” Cancer Research, Vol. 58, No. 8, 2008, pp. 2599-2609. doi:10.1158/0008-5472.CAN-07-5032

[24] S. R. Burzynski, R. A. Weaver, T. Janicki., B. Szymkowski, G. Jurida, M. Khan and V. Dolgopolov, "LongTerm Survival of High-Risk Pediatric Patients with Primitive Neuroectodermal Tumors Treated with Antineoplastons A10 AS2-1," Integrative Cancer Therapies, Vol. 4, No. 2, 2005, pp. 168-177. doi: $10.1177 / 1534735405276835$ 